\section{Update on statural growth and pubertal development in obese children}

\author{
Chiara De Leonibus, 1 \\ M. Loredana Marcovecchio,1,2 \\ Francesco Chiarelli1,2 \\ 1Department of Pediatrics, University \\ of Chieti; ${ }^{2}$ Center of Excellence on Aging, \\ G. D'Annunzio University Foundation, \\ University of Chieti, Italy
}

\begin{abstract}
Childhood obesity is a growing and alarming problem, associated with several short-term and long-term metabolic and cardiovascular complications. In addition, it has also been suggested that excess adiposity during childhood influences growth and pubertal development. Several studies have shown that during pre-pubertal years, obese patients present higher growth velocity and that this pre-pubertal advantage tends to gradually decrease during puberty, leading to similar final heights between obese and non-obese children. Excess body weight might also influence pubertal onset, leading to earlier timing of puberty in girls. In addition, obese girls are at increased risk of hyperandrogenism and polycystic ovary syndrome. In boys, a clear evidence does not exist: some studies suggesting an earlier puberty associated with the obesity status, whereas other have found a delayed pubertal onset. Overall, the existing evidence of an association between obesity and modification of growth and pubertal patterns underlines a further reason for fighting the epidemics of childhood obesity.
\end{abstract}

\section{Introduction}

Childhood obesity represents a growing and alarming problem as a result of the worldwide dramatic increase in its prevalence during the last decades. ${ }^{1}$ The World Health Organization defines childhood obesity as one of the most serious public health challenges of the 21 st century, due to its increasing prevalence at an alarming rate. In the USA $18.0 \%$ of children between 6 and 11 years and 18.4\% of adolescents has a body mass index (BMI) in the range of obesity. ${ }^{1}$ Similar trends have been observed in many European countries, where, based on the latest International Task Force criteria, overweight and obesity are present in $31.8 \%$ of school-aged children.2

Obesity has been associated with several short-term and long-term metabolic and cardiovascular complications, including impaired glucose metabolism, hypertension, dyslipidemia, fatty-liver disease and systemic lowgrade inflammation. ${ }^{2}$ Many of these complications are silent and often go undiagnosed during early stages. However they significantly influence short-term and long-term morbidity.

In addition to the increased cardio-metabolic risk, there is also evidence suggesting that childhood obesity can affect growth patterns and pubertal development. ${ }^{3-5}$ The aim of this review is to give an overview on the effect of childhood obesity on physical growth and pubertal development.

\section{Growth patterns in obese children}

Growth during childhood and adolescence is controlled by many factors including genes and hormones, with a main role of the growth hormone (GH)-insulin like growth factor-1 (IGF1) axis, thyroid hormones and sex steroids.,7,7 Several lines of evidence also support a major role of nutritional status in influencing childhood growth, as clearly evidenced by the association between short stature and malnutrition, ${ }^{8}$ as well as between overnutrition and tall stature. ${ }^{9}$

A number of studies have shown that, during pre-pubertal years, obese children present higher growth velocity and accelerated bone age compared to lean subjects. ${ }^{10,11}$ However, this pre-pubertal advantage in growth tends to gradually decrease during puberty, when obese children often show a reduced growth spurt compared to lean subjects. This latter effect, together with early pubertal maturation in obese children, determines similar final heights between obese and non-obese children. 3,4

Longitudinal studies have allowed a better characterization of growth patterns in obese children and adolescents. ${ }^{3,4}$ In particular, He et al. prospectively followed more than 3000 healthy Swedish children from birth to the age of 18 years. They observed that a greater rise in BMI from the age of 2 to 8 years was associated with taller height at the age of 8 years, earlier pubertal onset and reduced height gain during adolescence, but it was unrelated to adult height. This study showed that an increase in BMI of 1 unit led to an increase in height of $0.23 \mathrm{~cm}$ in boys and $0.29 \mathrm{~cm}$ in girls between ages 2 and 8 years. In addition, an increase in BMI of 1 unit reduced pubertal height gain of $0.88 \mathrm{~cm}$ in boys and $0.51 \mathrm{~cm}$ in girls, resulting in no beneficial effect on final height. ${ }^{3}$ Thus, although overnutrition during mid-childhood exerted a positive effect on height gain during childhood, there was no
Correspondence: Francesco Chiarelli,

Department of Pediatrics, University of Chieti via dei Vestini 5, 66100 Chieti, Italy.

Tel. +39.0871 .358015 - Fax: +39.0871 .574831$

E-mail: chiarelli@unich.it

Key words: growth, puberty, obesity, children.

Conflict of interests: the authors declare no conflict of interests.

Received for publication: 20 July 2012

Accepted for publication: 29 September 2012.

This work is licensed under a Creative Commons Attribution NonCommercial 3.0 License (CC BYNC 3.0).

(C) Copyright F. Chiarelli et al., 2012

Licensee PAGEPress, Italy

Pediatric Reports 2012; 4:e35

doi:10.4081/pr.2012.e135

positive effect on final height, likely due to the reduced height gain during adolescence. Similar results were obtained in the longitudinal study from Denzer et al. assessing anthropometric parameters in a large sample of German obese children $(n=1232)$ aged $6-18$ years. The main study finding was that mean height standard deviation score (SDS) was higher than in normal weight peers during childhood, but there was no difference by the age of 14 years. Thereafter, height SDS tended to be lower than in the reference population for both genders. A similar pattern was detected in bone age, which was significantly accelerated during childhood and early puberty, whereas in older subjects tended to be normal or even delayed. ${ }^{4}$

Taken together, these results underline a major role of nutrition in regulating human growth.

\section{Growth hormone-dependent growth: the growth hormone/insulin like growth factor- 1 axis in obese children}

It is well known that an intact GH/IGF-1 axis represents the key regulator of somatic growth in humans. However, childhood obesity is characterized by normal or even accelerated growth in spite of abnormalities in the GH/IGF1 axis, which are mainly characterized by reduced $\mathrm{GH}$ secretion with normal IGF-1 levels when compared to normal weight peers. Obese youth show a reduction in GH half-life, frequency of secretory bursts and daily production rate of GH. ${ }^{12}$ In particular, daily $\mathrm{GH}$ secretion and production rate have been calculated to fall 
by $6 \%$ for each unit increase in BMI, and $50 \%$ for an increase from 21 to $28 \mathrm{~kg} / \mathrm{m}^{2} .{ }^{13} \mathrm{GH}$ secretion is also impaired in response to all traditional stimuli acting at the hypothalamus.14,15 However, although GH secretion is blunted in obese children, their $\mathrm{GH}$ responsiveness appears to be increased compared to normal weight youth. At the peripheral level, increased GH binding protein (GHBP) values, corresponding to the extracellular domain of $\mathrm{GH}$ receptor, have been described in obesity. Therefore, it has been hypothesized that obese children present normal growth in spite of reduced GH secretion, probably because the combination of increased total GHBP (suggesting increased $\mathrm{GH}$ receptor number) and increased levels of GH-GHBP complex allow for the achievement of normal production and bioavailability of IGF-1 which, in turn, contributes to normal growth in obese children. ${ }^{16}$

Interestingly, the abnormalities in the GH/IGF-1 axis are reversible, as shown by the significant increase in $\mathrm{GH}$ secretion after a period of weight loss.17 Leptin has been hypothesized to be a potential link between obesity and impaired GH secretion. Serum leptin levels are elevated in simple obesity and in clinical conditions associated with increased body fat accumulation, ${ }^{18}$ such as Cushing's syndrome and adult GH deficiency.19-21 Leptin has been shown to exert a stimulating effect on $\mathrm{GH}$ release in fasted rodents. ${ }^{22}$ A similar effect has been hypothesized to occur in humans. Based on these data, the coexistence of high leptin and low GH serum levels in obesity would suggest a status of leptin resistance. 14

\section{Growth hormone-independent growth in obese children}

Somatic growth in obese children appears to be mainly $\mathrm{GH}$-independent, given that $\mathrm{GH}$ secretion is impaired. This growth without growth hormone phenomenon may be partially due to an increased insulin action on the IGF1 receptor, as a consequence of obesity-related insulin resistance. ${ }^{23}$ Additionally, insulin resistance may suppress IGF-binding protein 1 and 2, leading to greater IGF-1 bioavaliability and increasing linear growth. ${ }^{16}$ Altered sex steroid concentrations and adipokines released by the adipose tissue could play a role as well. It has been suggested that an increased adipose tissue aromatization of androgens into estrogens represents another important mechanism regulating growth in the context of obesity. ${ }^{24}$ Leptin appears to be an additional key factor mediating increased growth in the context of obesity. ${ }^{25}$ Animal models have shown that leptin can act as a skeletal growth factor, able to stimulate both prolifera- tion and differentiation of chondrocytes in the growth plate (Figure 1). ${ }^{26}$

\section{Pubertal onset/progression and childhood obesity}

Puberty is a period of physical and psychological maturation with long-term effects on health. Over the last decades a secular trend towards earlier puberty has occurred in association with improvements in nutrition and the increasing number of obese patients. ${ }^{27}$

The rising problem of childhood obesity has stimulated growing interest in the relationship between body composition during childhood and the timing and tempo of puberty. In North America and Europe, the age at the onset of menarche has declined from the age of 17 years in the mid-19th century to less than 14 years in the mid $20^{\text {th }}$ century. ${ }^{28}$ Similar trends have also occurred in the age at onset of thelarche and pubarche in girls. ${ }^{29-32}$ There are fewer records on the mean age at pubarche and testicular volumes changes in boys, so that data are insufficient to establish recent secular trends of pubertal onset in boys. ${ }^{33}$

Several cross-sectional studies have shown an association between increased BMI during childhood and early pubertal development in girls. ${ }^{29-32}$ Interestingly, not only childhood body size, but even early life factors might influence pubertal timing. Rapid early weight gain has been linked to elevated IGF-1 concentrations and insulin resistance, elevated adrenal androgen concentrations, exaggerated adrenarche, obesity, and consequently elevated concentrations of hormones such as leptin. It has been suggested that these factors could promote the activity of the gonadotropin-releasing hormone (GnRH) pulse generator, thereby influencing the timing of puberty. ${ }^{34}$ In particular, Terry et al. have found that size at birth and infant weight gain from 4 months to 1 year of life are associated with earlier age at menarche in girls. ${ }^{35}$ Other studies in this field have described similar results showing additive effects of pre- and postnatal growth on timing of menarche. ${ }^{36-38}$

In contrast, the relevance of early life risk factors for pubertal timing in boys is unclear, mainly because of the lack of an easily identifiable pubertal marker. However, a large study following a birth cohort of 6873 children from 1997, has recently suggested that, infant weight growth may be associated with earlier pubertal onset even in boys. ${ }^{39}$

Whereas the majority of studies have reported an anticipation of age at pubertal onset in obese girls, for boys the evidence is less clear with conflicting results. In fact, whereas most European studies have shown that obesity is associated with earlier puberty and voice break, $3,40-43$ American studies have mainly reported the opposite finding of obesity being associated with delayed puberty in boys. ${ }^{33,44-46}$ These discordant findings are partially

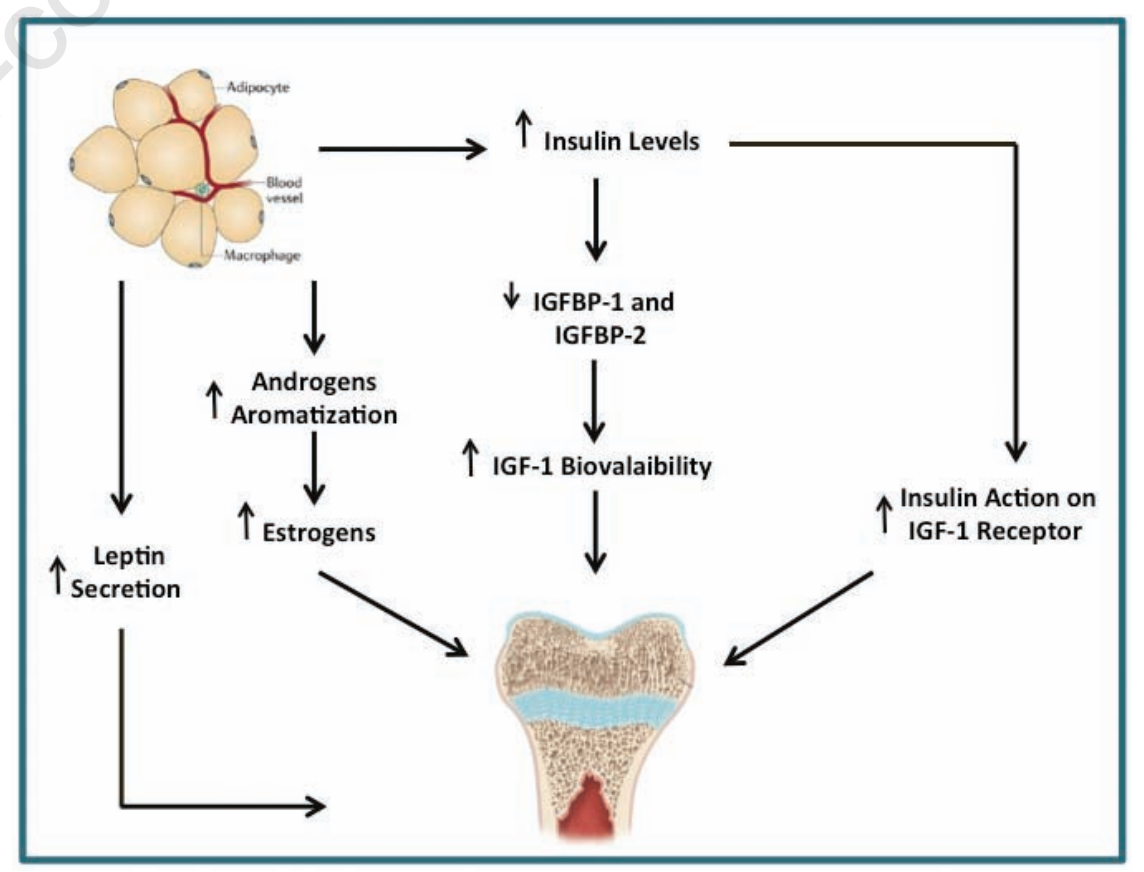

Figure 1. Mechanisms explaining growth hormone-independent growth in obese children. 
explained by the method of assessing puberty. A direct assessment of pubertal stage has been performed only in few studies, whereas others have been based on some surrogate markers of pubertal onset and progression, such as peak height velocity or age at voice break.

Furthermore, for both sexes, only few longitudinal studies have evaluated the effect of pre-pubertal body composition on pubertal onset and progression. ${ }^{31,43-46}$ The lack of longitudinal studies limits the possibility of defining the direction of the relationship between childhood obesity and pubertal maturation, in terms of which event comes first and hence influences the other. In fact, on the one hand, earlier puberty might be associated with a tendency of increasing fat deposition; whereas on the other hand, rapid weight gain might predispose to earlier puberty, but which event comes first has rarely been investigated, due to insufficient prospective studies in this field.

\section{Potential influence of obesity on pubertal onset: possible mechanisms}

The concept that childhood obesity might influence pubertal onset and progression is the dominant hypothesis. Several potential mechanisms underlying the effect of adipose tissue on pubertal onset have been recently described.
Adiposity has been proposed as a metabolic gatekeeper of central pubertal initiation, with a premature activation of the $\mathrm{GnRH}$ pulse generator. ${ }^{24}$ Leptin could represent the key factor mediating the effect of adiposity on central initiation of puberty; in fact, it has been shown to exert direct effects on gonadotropin secretion. 5

In addition, peripubertal obesity has been described to reduce sex hormone binding globulin (SHBG) levels, which in turn increase the bioavailability of sex steroids including estradiol. 32,47

Some studies suggest that at least in girls, an obesity-related estrogenization without true advancement of central (gonadotropindependent) puberty could occur. This hypothesis is supported by the observation that a high expression of aromatase in the adipose tissue is associated with estrogens production from adrenal androgen precursors. ${ }^{48,49}$ Finally, the status of hyperinsulinemia/insulin resistance associated with obesity might promote the onset and progression of puberty. Hyperinsulinemia might facilitate pubertal weight gain and growth as well as increase luteinizing hormone (LH)-stimulated ovarian and adrenal steroidogenesis.50,51 Increased androgen levels can, in turn, promote pubertal development acting peripherally and/or centrally on the hypothalamic pituitary axis. ${ }^{24}$ It has been supposed that increased androgen concentrations in pre-pubertal girls could facilitate pubertal increase of GnRH secretion, possibly leading to early pubertal onset (Figure 2). ${ }^{52}$

\section{Hyperandrogenism in obese girls and associated risks}

Peripubertal obesity in girls has been associated with hyperandrogenism. It has been found that, obese pre-puberal and pubertal girls presented higher testosterone levels, 4and 1.75-fold higher respectively, compared to their normal weight peers. Interestingly, these abnormalities appear to be reversible with weight loss. In the same group of children, it was shown a significant decrease in SHBG levels of $26 \%$ and $44 \%$ respectively, thus suggesting an increased bioavailability of androgen levels in obese girls. ${ }^{53}$ This might be related to hyperinsulinemia, which has been proven to raise serum testosterone levels in animal models, or to increased LH levels in obese children. ${ }^{47,54}$ In fact, obesity has been associated with low overnight LH pulse frequency in prepubertal and early pubertal girls, whereas by Tanner stage 3 to 5, LH frequency is abnormally elevated in obese girls, possibly reflecting the effects of hyperandrogenism. 55 Hyperan drogenism can be asymptomatic prior or during early puberty; whereas clinical manifestations can appear during early adolescence. The principal endocrine consequence of hyperandrogenism is an increased risk of developing polycystic ovary syndrome (PCOS). ${ }^{56}$ Few longitudinal studies have been performed to assess the contributing role of hyperandrogenism to the development of PCOS, but it has been shown that the prevalence of adolescents with PCOS has extensively increased in parallel with that of adolescent obesity. 57

\section{Conclusions}

Childhood obesity is related not only to wellknown cardiovascular and metabolic complications, but also to alterations in growth and pubertal patterns. Obese children show accelerated linear growth during pre-puberty, possibly due to early estrogenization and the action of insulin on the IGF-1 receptor. Subsequently, they show a trend toward a reduction of percentile for height in parallel with pubertal maturation, suggesting that pubertal growth spurt in obese children is at least less pronounced than in lean subjects, leading to similar final heights. Childhood obesity is even associated with early signs of puberty in girls and with either early or delayed puberty in boys. In addition, obese girls might experience hyperandrogenism due to increased total testosterone production and reduced SHBG, which represents a risk factor for the development of PCOS.

Overall, these data underline a further reason for fighting the epidemics of childhood obesity, that is preventing abnormal growth

Figure 2. Pathophysiology of earlier pubertal onset in obese children. 
and pubertal patterns.

Potential mechanisms leading to abnormal growth and pubertal patterns have been hypothesized, but many unanswered questions remain. For this reason, further studies should be performed in order to develop better screening tools for obesity-related complications and to allow the characterization of preventive treatments, beyond the achievement of normal weight.

\section{References}

1. Ogden CL, Carroll MD, Kit BK, et al. Prevalence of obesity and trends in body mass index among US children and adolescents, 1999-2010. JAMA 2012;307:48390.

2. Wang Y, Lobstein T. Worldwide trends in childhood overweight and obesity. Int $\mathrm{J}$ Pediatr Obes 2006;1:11-25.

3. He Q, Karlberg J. BMI in childhood and its association with height gain, timing of puberty, and final height. Pediatr Res 2001;49:244-51.

4. Denzer C, Weibel A, Muche R, et al. Pubertal development in obese children and adolescents. Int $\mathrm{J}$ Obes (London) 2007;31:1509-19.

5. Kaplowitz PB. Link between body fat and the timing of puberty. Pediatrics 2008;121 Suppl 3:S208-17.

6. Patel L, Clayton P. Normal and disordered growth. In: Clinical pediatric endocrinology. Brook C, Clayton P, Brown R, ed. Oxford: Blackwell; 2005. pp 90-112.

7. Wit JM, Camacho-Hubner C. Endocrine regulation of longitudinal bone growth. Endocr Dev 2011;21:30-41.

8. Rogol AD, Clark PA, Roemmich JN. Growth and pubertal development in children and adolescents: effects of diet and physical activity. Am J Clin Nutr 2000;72 Suppl 2:S521-8.

9. Forbes GB. Nutrition and growth. J Pediatr 1977;91:40-2.

10. Vignolo M, Naselli A, Di Battista E, et al. Growth and development in simple obesity. Eur J Pediatr 1988;147:242-4.

11. Davison KK, Susman EJ, Birch LL. Percent body fat at age 5 predicts earlier pubertal development among girls at age 9 . Pediatrics 2003;111:815-21.

12. Veldhuis JD, Iranmanesh A, Ho KKY, et al. Dual defects in pulsatile growth hormone secretion and clearance subserve the hyposomatotropism of obesity in man. $\mathrm{J}$ Clin Endocrinol Metab 1991;72:51-9.

13. Iranmanesh A, Lizarralde G, Veldhuis JD. Age and relative adiposity are specific negative determinants of the frequency and amplitude of growth hormone (GH) secre- tory bursts and the half-life of endogenous $\mathrm{GH}$ in healthy men. J Clin Endocrinol Metab 1991;73:1081-8.

14. Scacchi M, Pincelli AI, Cavagnini F. Growth hormone in obesity. Int J Obes 1999;23: 260-71.

15. Kreitschmann-Andermahr I, Suarez P, Jennings $\mathrm{R}$, et al. GH/IGF-I regulation in obesity-mechanisms and practical consequences in children and adults. Horm Res Paediatr 2010;73:153-60.

16. Ballerini MG, Ropelato MG, Domené HM, et al. Differential impact of simple childhood obesity on the components of the growth hormone-insulin-like growth factor (IGF)-IGF binding proteins axis. J Pediatr Endocrinol Metab 2004;17:749-57.

17. Argente J, Caballo N, Barrios V, et al. Multiple endocrine abnormalities of the growth hormone and insulin-like growth factor axis in prepubertal children with exogenous obesity: effect of short- and long-term weight reduction. J Clin Endocrinol Metab 1997;82:2076-83.

18. Considine RV, Sinha MK, Heiman ML, et al. Serum immunoreactive-leptin concentrations in normal-weight and obese humans. N Engl J Med 1996;334:292-95.

19. Leal-Cerro A, Considine RV, Peino R, et al. Serum immunoreactive-leptin levels are increased in patients with Cushing's syndrome. Horm Metab Res 1996;28:711-3.

20. Florkowski CM, Collier GR, Zimmet PZ, et al. Low-dose growth hormone replacement lowers plasma leptin and fat stores without affecting body mass index in adults with growth hormone deficiency. Clin Endocrinol (Oxf) 1996;45:769-73.

21. Fisker S, Vahl N, Hansen TB, et al. Serum leptin is increased in growth hormonedeficient adults: relationship to body composition and effects of placebo-controlled growth hormone therapy for 1 year. Metabolism 1997;46:812-7.

22. Carro E, Señaris R, Considine RV, et al. Regulation of in vivo growth hormone secretion by leptin. Endocrinology 1997; 138:2203-6.

23. Geffner ME. The growth without growth hormone syndrome. Endocrinol Metab Clin North Am 1996;25:649-63.

24. Burt Solorzano CM, McCartney CR. Obesity and the pubertal transition in girls and boys. Reproduction 2010;140:399-410.

25. Shalitin S, Phillip M. Role of obesity and leptin in the pubertal process and pubertal growth-a review. Int $\mathrm{J}$ Obes Relat Metab Disord 2003;27:869-74.

26. Maor G, Rochwerger M, Segev Y, et al. Leptin acts as a growth factor on the chondrocytes of skeletal growth centers. J Bone Miner Res 2002;17:1034-43.

27. Wagner IV, Sabin MA, Pfäffle RW, et al. Effects of obesity on human sexual devel- opment. Nat Rev Endocrinol 2012;8:24654.

28. Parent AS, Teilmann G, Juul A, et al. The timing of normal puberty and the age limits of sexual precocity: variations around the world, secular trends, and changes after migration. Endocr Rev 2003;24:68893.

29. Kaplowitz P. Pubertal development in girls: secular trends. Curr Opin Obstet Gynecol 2006;18:487-91.

30. Rosenfield RL, Lipton RB, Drum ML. Thelarche, pubarche, and menarche attainment in children with normal and elevated body mass index. Pediatrics 2009;123:84-8.

31. Aksglaede L, Juul A, Olsen LW, et al. Age at puberty and the emerging obesity epidemic. PLoS One 2009;4:e8450.

32. Ahmed ML, Ong KK, Dunger DB. Childhood obesity and the timing of puberty. Trends Endocrinol Metab 2009;20:23742.

33. Euling SY, Herman-Giddens ME, Lee PA, et al. Examination of US puberty-timing data from 1940 to 1994 for secular trends: panel findings. Pediatrics 2008;121 Suppl 3:S172-S191.

34. Dunger DB, Ahmed ML, Ong KK. Early and late weight gain and the timing of puberty. Mol Cell Endocrinol 2006;254-255:140-5.

35. Terry MB, Ferris JS, Tehranifar P, et al. Birth weight, postnatal growth, and age at menarche. Am J Epidemiol 2009;170:72-9.

36. Adair LS. Size at birth predicts age at menarche. Pediatrics 2001;107:E59.

37. Sloboda DM, Hart R, Doherty DA, et al. Age at menarche: influences of prenatal and postnatal growth. J Clin Endocrinol Metab 2007;92:46-50.

38. Tam CS, de Zegher F, Garnett SP, et al. Opposing influences of prenatal and postnatal growth on the timing of menarche. $J$ Clin Endocrinol Metab 2006;91:4369-73.

39. Hui LL, Wong MY, Lam TH, et al. Infant growth and onset of puberty: prospective observations from Hong Kong's children of 1999 birth cohort. Ann Epidemiol 2012;22: 43-50.

40. Juul A, Magnusdottir S, Scheike T, et al. Age at voice break in Danish boys: effects of pre-pubertal body mass index and secular trend. Int J Androl 2007;30:537-42.

41. Monteilh C, Kieszak S, Flanders WD, et al. Timing of maturation and predictors of Tanner stage transitions in boys enrolled in a contemporary British cohort. Paed Perinat Epidemiol 2011;25:75-87.

42. Vizmanos B, Marti-Henneberg C. Puberty begins with a characteristic subcutaneous body fat mass in each sex. Eur J Clin Nutr 2000;54:203-8.

43. Ong KK, Bann D, Wills AK, et al. Timing of voice breaking in males associated with 
growth and weight gain across the life course. J Clin Endocrinol Metab 2012;97:2844-52.

44. Wang Y. Is obesity associated with early sexual maturation? A comparison of the association in American boys versus girls. Pediatrics 2002;110:903-10.

45. Lee JM, Kaciroti N, Appugliese D, et al. Body mass index and timing of pubertal initiation in boys. Arch Ped Adolesc Med 2010;164:139-44.

46. Buyken AE, Karaolis-Danckert N, Remer T. Association of prepubertal body composition in healthy girls and boys with the timing of early and late pubertal markers. Am J Clin Nutr 2009;89:221-30.

47. McCartney CR, Blank SK, Prendergast KA, et al. Obesity and sex steroid changes across puberty: evidence for marked hyperandrogenemia in pre- and early pubertal obese girls. J Clin Endocrinol
Metab 2007;92:430-6.

48. Dunger DB, Ahmed ML, Ong KK. Effects of obesity on growth and puberty. Best Pract Res Clin Endocrinol Metab 2005;19:375-90.

49. Jasik CB, Lustig RH. Adolescent obesity and puberty: the perfect storm. Ann N Y Acad Sci 2008;1135:265-79.

50. Lee JM. Insulin resistance in children and adolescents. Rev Endocr Metab Disord 2006;7:141-7.

51. Poretsky L, Cataldo NA, Rosenwaks Z, et al. The insulin-related ovarian regulatory system in health and disease. Endocr Rev 1999;20:535-82.

52. Blank SK, McCartney CR, Chhabra S, et al. Modulation of gonadotropin-releasing hormone pulse generator sensitivity to progesterone inhibition in hyperandrogenic adolescent girls-implications for regulation of pubertal maturation. J Clin Endocrinol Metab 2009;94:2360-6.
53. Reinher T, de Sousa G, Roth CL, et al. Androgens before and after weight loss in obese children. J Clin Endocrinol Metab 2005;90:5588-95.

54. Chakrabarty S, Miller BT, Collins TJ, et al. Ovarian function in peripubertal hyperinsulinemia. J Soc Gynecol Investig 2006;13: 122-9.

55. McCartney CR, Prendergast KA, Blank SK, et al. Maturation of luteinizing hormone (gonadotropin-releasing hormone) secretion across puberty: evidence for altered regulation in obese peripubertal girls. $\mathrm{J}$ Clin Endocrinol Metab 2009;94:56-66.

56. Rosenfield RL. Clinical review: identifying children at risk for polycystic ovary syndrome. J Clin Endocrinol Metab 2007; 92:787-96.

57. Franks S. Polycystic ovary syndrome in adolescents. Int J Obes (Lond) 2008;32: 1035-41. 